\title{
Understanding the Profound Connotation of the Important Speech on July 1st from the Historical Value, Practical Value and Theoretical Value
}

\author{
Jia Wen \\ School of Marxism, Lianyungang Normal College, Lianyungang, China \\ Email: 410695438@qq.com
}

How to cite this paper: Wen, J. (2021) Understanding the Profound Connotation of the Important Speech on July 1st from the Historical Value, Practical Value and Theoretical Value. Open Access Library Journal, 8: e8058.

https://doi.org/10.4236/oalib.1108058

Received: October 8, 2021

Accepted: October 22, 2021

Published: October 25, 2021

Copyright $\odot 2021$ by author(s) and Open Access Library Inc.

This work is licensed under the Creative Commons Attribution International License (CC BY 4.0).

http://creativecommons.org/licenses/by/4.0/

(c) (i) Open Access

\begin{abstract}
General Secretary Xi Jinping's important speech on July 1st is an important political declaration made by China at the critical moment of the intersection of two centuries for the whole country and the world. It is a highly condensed and generalized history of our party's one-hundred-year struggle. At the same time, it is also on the basis of tracing history, based on the reality of China's development, and provides programmatic guidance for the future development of the party and the country. It is also an action guide for the ultimate realization of the Chinese dream of the great rejuvenation of the Chinese nation, and it plays a very important role in achieving the goal of the next century. Based on three aspects, this article deeply explores the historical value and profound connotation of the important speech on July 1st from the perspective of Chinese history, community consciousness and "Two Combinations". In order to fully understand the great achievements, valuable experience and basic laws of the Chinese Communist Party in a century of struggle history are researched systematically.
\end{abstract}

\section{Subject Areas}

Politics

\section{Keywords}

The Important Speech on July 1st, Historical Value, Practical Value, Heoretical Value 


\section{1. 引言}

习近平总书记在庆祝中国共产党成立 100 周年大会上的重要讲话全文 7310 个字, 脉络清晰、结构严谨, 提出了很多新提法、新论述、新理念和新 观点, 整篇讲话脉络清晰、逻辑严密, 在回溯历史的基础上, 立足现在并展 望未来, 为我们进一步推进新时代中国特色社会主义伟大事业提供了强有力 的智力支持和思想指南。因此, 系统学习 “七一” 重要讲话精神具有十分重 要的理论和现实意义。本文力求从历史价值、实践价值和理论价值三个层面 对 “七一” 重要讲话进行具体分析, 深刻领会其中的重要内涵, 从而指导我 们向着下一个百年目标胜利前行。

\section{2. 立足中国大历史：理解 “七一”重要讲话的历史价值}

习近平总书记在 “七一” 重要讲话中强调: “中华民族是世界上伟大的 民族, 有着 5000 多年源远流长的文明历史, 为人类文明进步做出了不可磨灭 的贡献。1 840 年鸦片战争以后, 中国逐步成为半殖民地半封建社会, 国家蒙 辱、人民蒙难、文明蒙尘, 中华民族遭受了前所未有的劫难。从那时起, 实 现中华民族伟大复兴, 就成为中国人民和中华民族最伟大的梦想” ([1]: p. 2)。 因此, 思考中国共产党的伟大, 必须立足中国大历史, 通过发展的抛物线更 加深刻地理解中国共产党诞生的伟大历史意义, 这就要求我们不能简单地从 百年党史发展历程分析中国共产党的奋斗历程, 而是综合中华文明几千年发 展历程, 通过深刻挖掘 “复兴”一词的内涵, 更好地理解为什么必须坚持中 国共产党的领导。

“复兴” 的含义为 “衰落后再兴盛起来, 再创辉煌”, 中国曾经是四大 文明古国之一, 中华文明是世界上最古老的文明之一, 也是世界上持续时间 最长的文明。中国在漫长的世界古代历史发展进程中一直独树一帜, 甚至在 相当长的时期内中国成为世界政治、经济和文化发展的中心之一。应该说, 中国人在漫长而灿烂的古代社会是不会预见进入近代社会后中国发生的翻天 覆地的变化, 也不会想到中国会从一个泱決大国急速坠落, 成为任人欺凌的 半殖民地半封建社会, 经历百年屈辱, 自然在漫长的历史演进过程中, 中国 不会发生剧烈的社会变革, 尤其是社会性质翻天覆地的变化。因此, 是中国 客观历史的发展造就了中国社会的发展变化, 任何历史因素绝对不是靠主观 臆断产生的, 评价中国共产党的诞生以及其在中国近现代史进程中的历史作 用、历史地位必须建立在辩证唯物主义和历史唯物主义的基础上, 任何夸大 或是贬低都是不正确的, 都是对中国客观历史的不尊重。

近代鸦片战争后, 中国被帝国主义的坚船利炮打开了国门, 侵略者蜂拥 而至, 给中国和中华民族造成了难以磨灭的伤害, 中国逐渐沦为一个半殖民 地半封建的国家, 中国人民生活在水深火热之中。客观上中国社会在近代自 救的过程中, 并不是从一开始就选择了中国共产党, 事实上地主阶级、农民 阶级和资产阶级都曾经按照自己的方式进行了自救运动, 但客观结果是没有 任何一个能改变中国的命运, 没有一个能领导中国最终取得国家独立、民族 解放的历史重任, 也正是在这样客观史实的基础上, 中国人民只能开始依靠 
崭新的阶级, 探索崭新的发展道路。十月革命一声炮响给中国送来了马克思 列宁主义, 五四运动之后用先进理论武装起来的中国共产党登上引领中华民 族改变命运、走向复兴的历史舞台, 这是历史客观必然性推动的结果, 不以 任何个人的主观意志为转移。

“中国共产党一经诞生, 就把为中国人民谋幸福、为中华民族谋复兴确 立为自己的初心使命。一百年来, 中国共产党团结带领中国人民进行的一切 奋斗、一切牺牲、一切创造, 归结起来就是一个主题: 实现中华民族伟大复 兴。” ([1]: p. 3)。伟大的历史实践证明直到中国共产党登上历史舞台, 才最 终实现了几代中国人的网愿, 那就是国家独立、民族解放, 这是不容置疑的 事实。是中国共产党领导中国人民进行了艰苦卓绝的斗争, 才实现中国由不 断衰落到根本扭转命运、持续走向繁荣富强的伟大飞跃, 肩负起了实现中华 民族伟大复兴的历史使命, 历史证明了中国选择党的领导的必然性和必要性、 证明了中国共产党领导的正确性、证明中国共产党领导中国取得革命、改革 与建设成功的巨大历史意义、政治意义、理论意义、实践意义和世界意义。

在中国共产党的领导下, 进入新时代的中国实现了第一个百年奋斗, 全 面建成小康社会, 消除了绝对贫困, 向着全面建成社会主义现代化强国的第 二个百年奋斗目标奋勇前进。应该说立足大历史观, 结合中国几千年的发展 曲线就能更加深刻地把握 “七一” 重要讲话中提及的 “没有中国共产党, 就 没有新中国，就没有中华民族伟大复兴” ([1]: pp. 10-11)。中华文明几千年的 发展历程, 从漫长的波峰自近代跌至波谷, 直到中国共产党诞生后才又不断 披荆斩棘、突破重重阻碍, 重新回到世界舞台的中心, 中国历史与现实的客 观发展历程证明了必须坚持党的集中统一领导, 这一点不容置疑, 必须毫不 动摇。

\section{3. 把握共同体意识: 理解 “七一” 重要讲话的实践价值}

“共同体是具有共同价值取向的人的联结, 其内涵是在共同体里每个人 都能实现自由全面的发展” [2]。“七一” 重要讲话中尤为突出的一点就是强 调 “共同体” 意识, 这种意识体现在我们党革命、建设和改革的全过程, 体 现在中国共产党处理对内和对外事务的全过程, 具有非常鲜明的中国传统文 化优势, 同时也充分体现了中国共产党作为高举马克思主义旗帜的使命型政 党, 其具备的与资产阶级政党截然不同的执政理念、执政目的, 充分体现了 中国共产党的执政优势。

\section{1. 把握共同体意识, 始终坚持一切为了人民、一切依靠人民}

中国民本思想源远流长, 几千年来无数思想家从不同角度阐释了民本思 想的价值与内涵, 如孟子的 “民为贵, 社稷次之, 君为轻” , 西汉刘安《淮 南子 - 泛论训》中的 “治国有常, 而利民为本” 都体现出朴素的民本观。中 国共产党自诞生之日，其一贯坚持的奋斗目标就体现了对 “民本”、“利民” 思想的继承，尤其表现在为整个中华民族、全体中国人民服务的 “共同体” 意识。“中国共产党自成立以来, 就把为中国人民谋幸福、为中华民族谋复 兴确立为自己的初心使命。把人民过上好日子和民族实现伟大复兴, 作为自 
己矢志不渝的奋斗目标和根本追求。她之所以能够发展壮大、取得成功, 根 本原因是由她的政党性质和宗旨决定的，她来自人民、依靠人民、为了人民” [3]。革命战争年代, 中国共产党带领全体中国人民在极端恶劣甚至濒临绝境 的环境里通过不解斗争, 战胜国内国外一切敌人, 最终实现了国家独立、民 族解放, 中国人民摆脱了被奴役、被侵略的历史; 建设和改革时期中国共产 党坚守初心和使命, 立志为全体中国人民的幸福生活不解奋斗, 一步步把贫 穷落后的旧中国建设成为现在举世瞩目的新兴经济体, 在经济、政治、科技、 文化、军事等全方位取得了举世瞩目的发展成绩。应该说, 中国革命、建设 和改革的全过程都充分证明中国共产党始终坚持一切为了人民、一切依靠人 民, 始终把人民放在心中最高位置、把人民对美好生活的向往作为奋斗目标, 推动发展成果具有更加广泛的普惠性。中央财经委员会第十次会议上, 习近 平总书记发表重要讲话再次强调共同富裕是社会主义的本质要求, 是中国式 现代化的重要特征, 中国的发展必须坚持以人民为中心的发展思想, 在高质 量发展中促进共同富裕。中国共产党领导中国发展的实践充分显示了其作为 马克思主义使命型政党的优势, 发展过程中体现出的鲜明的 “共同体” 意识 是我们党区别于其他一切政党尤其是资产阶级政党的根本标志。

同时, 在这次 “七一” 重要讲话中, 习近平总书记还把整个中华民族的 团结提到非常重要的位置, 强调必须加强中华儿女大团结汇聚, 实现中华民 族复兴的磅礴力量。2019 年 10 月, 中共中央办公厅、国务院办公厅印发的《关 于全面深入持久开展民族团结进步创建工作铸牢中华民族共同体意识的意 见》就曾指出 “中华民族共同体意识是国家统一之基、民族团结之本、精神 力量之魂”。党的十九届四中全会审议通过的《中共中央关于坚持和完善中 国特色社会主义制度、推进国家治理体系和治理能力现代化若干重大问题的 决定》全面总结了中国特色社会主义制度建设的历史性成就, 集中概括了中 国特色社会主义制度和国家治理体系的 13 个显著优势, “坚持各民族一律平 等, 铸牢中华民族共同体意识, 实现共同团结奋斗、共同繁荣发展” 是其中 的优势之一。今年 8 月, 习近平总书记在中央民族工作会议上再次强调必须 以筑牢中华民族共同体意识为主线, 推动新时代党的民族工作高质量发展, 应该说 “习近平总书记站在党和国家事业发展全局的战略高度, 深入阐明铸 牢中华民族共同体意识的重大意义, 强调必须以铸牢中华民族共同体意识为 新时代党的民族工作的主线, 推动各民族坚定对伟大祖国、中华民族、中华 文化、中国共产党、中国特色社会主义的高度认同，不断推进中华民族共同 体建设” [4], 这体现了中国共产党始终铸牢中华民族共同体意识, 坚持各民 族平等, 实现各民族共同发展、共同繁荣的执政理念, 体现了中国共产党的 执政优势, 证明了只有中国共产党才能领导中华民族永续发展, 并在此基础 上实现中华民族伟大复兴的中国梦。

\section{2. 把握共同体意识, 致力于推动构建人类命运共同体}

习近平总书记在 “七一” 重要讲话提及的 “九个必须” 战略部署中强调 “必须不断推动构建人类命运共同体”，“中国始终是世界和平的建设者、 全球发展的贡献者、国际秩序的维护者” ([1]: p. 16), 这段讲话体现了中国共 
产党坚持的 “共同体” 意识的另一个重要层面, 即中国必将在中国共产党的 领导下关注整个人类的前途命运、推动构建人类命运共同体, 肩负起一个马 克思主义政党的历史使命。

“和平、和睦、和谐是中华民族 5000 多年来一直追求和传承的理念” ([1]: p. 16), 中国优秀灿烂的传统文化中, “和” 的思想一直备受关注、深入人心, 是中国人一贯追求的价值目标, 也是始终贯彻的处世原则。著名的《礼记》 就阐明了 “天下为公” 的社会模式, 提倡 “和而不同” 、“美人之美, 美美 与共”。习近平总书记 “七一” 重要讲话充分体现了中国共产党是中国优秀 传统文化的继承者、发展者, 中国共产党领导的中国始终坚持走和平发展道 路, 推动构建人类命运共同体, 为世界发展提供中国智慧、中国方案, 以期 推动全世界, 尤其是落后国家和地区的发展, 推动人类文明的进步, 因此, 这一 “共同体” 理念符合人类历史发展趋势, 也符合世界人民追求和平与发 展的朴素愿望。

同时, 我们在理解这一 “共同体” 概念时还要认识一个重要问题, 即它 不仅仅体现在利益层面, 更多是强调同舟共济、荣辱与共的命运层面, 尤其 表现在构建卫生健康共同体、安全共同体、人文共同体等领域。当今世界处 于百年未有之大变局, 世界发展遇到如新冠肺炎疫情等的新问题、新挑战, 西方为主导的国际秩序旧原则、旧方法已无法适应新的历史发展变化, 也无 法解决当今世界出现的危机挑战。中国共产党提出的 “构建人类命运共同体” 理念以建设一个持久和平、普遍安全、共同繁荣、开放包容、清洁美丽的世 界为目标, 符合历史发展规律、符合世界各国人民的共同价值追求, 是应对 新的全球变局科学之策, 这一 “共同体” 理念充分体现了中国共产党是为整 个人类进步事业而奋斗的政党, 是始终把为人类做出新的更大的贡献为使命 的马克思主义政党。

\section{3. 把握共同体意识, 有效推动建设生命共同体}

中国共产党的执政理念中始终坚持人与自然和谐共生的科学发展观, 习 近平总书记在 “领导人气候峰会” 上发表题为 “共同构建人与自然生命共同 体” 的重要讲话, 把 “人与自然生命共同体” 理念纳入 “人类命运共同体” 的构建体系。“七一” 重要讲话中, 习近平总书记强调在中国共产党领导下, 中国 “推动物质文明、政治文明、精神文明、社会文明、生态文明协调发展, 创造了中国式现代化新道路，创造了人类文明新形态” ，中国 “坚持人与自 然和谐共生, 协同推进人民富裕、国家强盛、中国美丽” ([1]: p. 14)。

应该说, 中国共产党倡导建设 “生命共同体” 是科学应对中国国内乃至 整个世界发展的积极方式。从中国发展的客观实际看, 前期经济高位运行过 程中对资源与环境的破坏所产生的生态问题开始一一出现; 从世界发展大环 境看, 人类工业文明发展进程中对整个地球生态系统平衡的毁灭性打击给全 人类的生存和发展带来严峻挑战, 也引发了全球发展危机。因此, 必须采取 有效措施构建人与自然和谐发展的生态文明新形态以解决日益严峻的环境问 题, 正是在这样的大背景下, 习近平总书记提出了构建 “生命共同体” 的理 念, 这一理念充分吸收了中国传统文化中 “天人合一” 的和谐发展观, 同时 
继承并发展了马克思主义生态观, 强调在承认和尊重自然环境及其客观发展 规律的基础上实现人类社会与自然的和谐共生, 从而形成能实现良性循环的 新的生态社会系统, 为解决中国乃至世界发展进程中的问题提出了崭新方案, 体现了中国式现代化发展路径、发展模式的强大优势。

\section{4. 剖析 “两个相结合” ：理解 “七一”重要讲话的理论价值}

习近平总书记 “七一” 重要讲话在论及马克思主义中国化时, 强调了 “两 个相结合” ，即 “坚持把马克思主义基本原理同中国具体实际相结合、同中 华优秀传统文化相结合” ([1]: p. 13), 在突出坚持马克思主义为指导的基础上, 强调中华优秀传统文化根源, 丰富和发展了马克思主义中国化的科学内涵, 具有非常重要的理论价值和实践意义。

\section{1. 马克思主义理论必须与中国发展实际相结合}

脱离科学理论指导的政党是无法成功的, 中国历史与现实的发展都证明 了马克思主义是我们立党立国的根本指导思想, 是保证我们社会主义事业不 断取得成果的根本所在, 中国共产党带领中国人民攻坚克难, 取得一系列伟 大胜利的重要法宝之一就是始终坚持以马克思主义理论为指导。但是马克思 主义理论不是僵化保守的戒条, 而是具有与时俱进鲜明特点的科学思想体系, 是指导实践的科学世界观和方法论, 其内在品格决定了马克思主义理论具有 客观性、实践性、开放性的本质, 必须把理论与不同时期不同环境的具体实 践相结合，才能发挥马克思主义理论的巨大指导作用。

中国共产党自成立伊始就坚持把马克思主义普遍真理同中国具体实际相 结合, 同中国优秀传统文化相结合, 不断推动马克思主义中国化。1938 年党 的扩大的六届六中全会上, 毛泽东同志首次对马克思主义中国化问题做出深 刻论述, 指出马克思主义的实现必须和中国具体特点相结合并且一定要通过 一定的民族形式, 邓小平同志同样指出中国需要的真正的马克思主义是结合 中国实际的马克思主义, “七一” 重要讲话中, 习近平总书记指出, “马克 思主义是我们立党立国的根本指导思想, 是我们党的灵魂和旗帜。中国共产 党坚持马克思主义基本原理, 坚持实事求是, 从中国实际出发, 洞察时代大 势, 把握历史主动, 进行艰辛探索, 不断推进马克思主义中国化时代化, 指 导中国人民不断推进伟大社会革命。” ([1]: pp. 12-13)。由此可见, 中国共产 党的百年奋斗史是与马克思主义中国化的历史进程高度统一的, 在接续探索 中中国共产党形成了毛泽东思想、邓小平理论、三个代表重要思想、科学发 展观以及习近平新时代中国特色社会主义理论在内的一系列重大理论成果, 进行了一系列理论创新, 丰富并发展了科学社会主义, 开辟了当代马克思主 义的新境界。

\section{2. 马克思主义理论必须与中国优秀传统文化相结合}

在马克思主义中国化的进程中, 还必须考虑中国优秀传统文化因素。习 近平总书记在十九大报告指出: “文化是一个国家、一个民族的灵魂。文化 兴国运兴, 文化强民族强。没有高度的文化自信, 没有文化的繁荣兴盛, 就 
没有中华民族伟大复兴。” ([5]: pp. 40-41)。中国的基本国情之一就是历史文 化悠久, 有着深厚的文化土壤, 我们整个国家、整个民族的形成与发展都建 立在具有悠久传统文化背景下的历史发展与积淀的基础上, 这一点不容置疑, 也是我们在理论建设和社会发展过程中必须考虑的本源性问题, 因此, 在推 进马克思主义中国化的过程中, 必须充分结合中华民族最基本的文化基因, 否则理论只能是无源之水, 无本之木, 是无法正确指导中国特色社会主义发 展的。另一方面, 中国在马克思主义中国化的进程中, 在马克思主义理论与 中国传统文化相结合的过程中, 致力于加强对传统文化的价值挖掘, 推动了 传统文化的创新与发展, 使其在新时期焕发出新的生机与活力, 从而使其进 一步与中国特色社会主义建设事业相一致, 与新的发展阶段相协调, 为实现 中华民族伟大复兴提供重要的精神力量。

\section{5. 结论}

综上所述, 习近平总书记在庆祝中国共产党成立 100 周年大会上的重要 讲话是一篇马克思主义的纲领性文献, 其内涵丰富, 在全面系统总结历史经 验的基础上为未来中国的发展提供了新的行动指南, 是指引我们向第二个百 年奋斗目标迈进, 实现中华民族伟大复兴的行动指南, 对中国乃至全人类的 进步事业都具有非常重要的理论价值和现实意义。

本文充分运用辩证唯物主义和历史唯物主义观点, 立足历史价值、实践 价值和理论价值, 对习近平总书记在中国共产党成立 100 周年大会上的重要 讲话的伟大意义和深刻内涵进行了分析, 深入挖掘 “七一” 重要讲话中阐述 的新理论新观点的历史意义和时代价值, 并将对这一文本的研究同四史学习、 “七一勋章” 颁授仪式上的重要讲话以及习近平总书记在世界政党领导人峰 会上的主旨讲话的研究相结合, 提炼习近平总书记系列讲话中的共性思想, 形成对这一重要讲话的长效研究。

与此同时, 对 “七一” 重要讲话的理解与研究绝不局限于上述三个方面, 讲话中对于全面建成小康社会历史性成就的重要论述、中国共产党伟大建党 精神及其理论创新的重要论述、中国共产党建设规律和执政规律的重要论述 以及中国式现代化新道路的重要论述等都具有非常重要的研究价值, 因此必 须深化对 “七一” 重要讲话的研究, 把研究成果转化为新时代建设中国特色 社会主义的实践动力, 推动中华民族伟大复兴中国梦的目标早日实现。

\section{基金项目}

本文为 “学习习近平总书记 “七一” 重要讲话精神” (21LKTZ0018)连云 港市社科基金项目专项课题终期研究成果。

\section{Conflicts of Interest}

The author declares no conflicts of interest.

\section{References}

[1] 习近平. 在庆祝中国共产党成立 100 周年大会上的讲话[M]. 北京: 人民出版社, 
2021.

[2] 查正权. 马克思共同体概念的澄明[N]. 中国社会科学报, 2020-07-22.

[3] 杨明伟. 读懂中国共产党一一中国共产党的历史使命与行动价值》解析 [N]. 学 习时报, 2021 年 9 月 10 日.

[4] 人民网. 深刻认识铸牢中华民族共同体意识的重大意义一一论学习贯彻习近平 总书记中央民族工作会议重要讲话[N]. 人民日报评论员文章, 2021-08-30.

[5] 习近平. 决胜全面建成小康社会 夺取新时代中国特色社会主义伟大胜利一一在 中国共产党第十九次全国代表大会上的报告(2017 年 10 月 18 日) [M]. 北京：人 民出版社, 2017.

\section{Appendix (Abstract and Keywords in Chinese)}

\section{从历史价值、实践价值和理论价值理解 “七一” 重要讲话的深刻内涵}

摘要：习近平总书记 “七一”重要讲话是中国处于两个百年交汇点关键时刻 面向全国、面向世界做出的重要政治宣言, 是对我们党一百年奋斗征程史的 高度凝练与概括，同时也是在回溯历史的基础上、立足中国发展的现实并对 党和国家未来事业的发展做出纲领性的指导，是最终实现中华民族伟大复兴 中国梦的行动指南, 为实现下一个百年奋斗目标凝心聚气具有十分重要的作 用。本文立足三个方面，从中国大历史、共同体意识和 “两个结合” 深入挖 掘 “七一” 重要讲话的历史价值和深刻内涵, 以期通过系统研究更加充分认 识中国共产党百年奋斗历史的伟大成就、宝贵经验与基本规律。

关键词: “七一” 重要讲话, 历史价值, 实践价值, 理论价值 